DOI: $10.51480 / 1899-5101.14 .1(28) .13$

\title{
TERRY FLEW (2018). UNDERSTANDING GLOBAL MEDIA. SECOND EDITION. LONDON: PALGRAVE MACMILLAN, 227 PP., ISBN: 978-1-137-44653-4.
}

Written by internationally recognised Australian scholar and Media and Communication professor Terry Flew, Understanding Global Media presents readers with a comprehensive, in-depth analysis of communications media and its relations to various aspects of modern societies. Some examples of these aspects are political and media cultures, media policies and national media systems, modern production and consumer culture, and the questions of identities within a globalised world. Being the second edition of the 2007 original, the textbook proves to be a rather up-to-date source of information about global media. The author covers events such as the 2016 election of Donald Trump and the Brexit referendum, and analyses their lasting consequences and what we can learn from them on the subjects of, among other things, global media and communications, the role of nation-states and the dilemma between national and cosmopolitan identities, and even media economics.

In his work, Flew presents us with a well-structured and extremely thorough overview and precise analysis on the different approaches of global media with special emphasis on the different theories of modernisation, political economy and globalisation, all of which are more closely explored in their respective dedicated chapters. Flew not only describes and compares the different approaches, but also places them in a historical overview, enabling us, the readers, to gain a valuable insight of how the examined approaches changed over time in accordance with the various socio-cultural, political and technological changes.

Carefully displayed groundwork ensures even readers without excessive background knowledge regarding modernisation and globalisation theories can easily follow his arguments. Flew then presents us with a wide range of perspectives, with which he explores the connections and interdependencies between, for instance, global media and national governments, participatory communication and media consumption, network society, cultures and technological systems, as well as media geography and global media production. While doing so, Flew also supports and illustrates his arguments through various case studies, one of them being the exemplification of the co-productions of movies between China and the United States in the late 2000s and 2010s. This endeavour seemed to be blooming despite the obvious political and ideological differences, and 
the fact that the two countries have been increasingly seen as rivals for global leadership.

Additionally, to the author's evident knowledge in the explored fields, the tone of the book is also refreshing. Since all of the explored concepts and theories are put into a greater perspective, it results in an unbiased end-product that approaches all questions and debates by considering all sides of the arguments. This aspect seems to be all the more important as it allows the author to take a unique approach towards the analysed material, which tends to be the most visible in the case of globalisation theories.

Flew argues, for example, that while overstating the extent, to which ostensibly global companies have been able to disconnect their pursuits from national governments, in many cases such corporations are rather just national actors with external operations that tend to face a strong competition from local competitors. In close connection with that assumption, a tendency to understate the significance of national identity and the importance of national-cultural symbols can also be observed, even though television studies have long shown that media consumers generally prefer local content over anything imported when presented with a choice. Globalisation theorists however tend to see connections both between culture and identity and between nation-states and national media systems in a sense that they are all becoming increasingly de-territorialized, resulting in "the proliferation of identities that are less and less connected to nation-states" (p. 188). Consequently, these theories also tend to link these 'post-national' identities and the growing role of NGOs and civil society in shaping governance, hence decreasing the attributed importance to the pull factors of national identities.

By analysing a diverse works of authors such as Giddens, Castells and Appadurai, Flew concludes that we get rather conflicting messages regarding the role of nations and nation-states which - as he convincingly argues - continue to have considerable significance. Accordingly, he states that while globalisation theories tend commonly to see global media and communication as of the utmost importance in determining the nature of production and consumption, culture and identity, practices of power and governance, they also tend to underestimate said continuing significance of nation-states. As Flew explains (p. 98):

"On the one hand, globalisation is seen as deterritorialising production, power and culture to such a degree that it no longer makes sense to focus on the national level, and that substantive engagement requires a turn to supranational or even global form of governance. On the other hand, the continuing and possibly growing, strength of national media systems, and the proliferation of new media capitals around the globe suggest that globalism per se is a less powerful force than is being sometimes assumed, and that the 
international expansion of media is driven more by regional or geolinguistic dynamics than by those of an omnipotent global culture".

He adds that it is also important to note that certain movements that have challenged the power of nation-states in the past have themselves been of a nationalistic nature (such as the Scottish, the Catalan or the Basque nationalist movements), while resistance towards globalisation can also manifest in the form of nationalism. Flew points out that with the Brexit referendum and the elections of leaders such as Trump in the United States, Erdoğan in Turkey, Orbán in Hungary and Kaczyński in Poland, the 2010s provided us with a noticeably high number of examples to illustrate the latter case.

As a conclusion to his detailed work, Flew reminds us that even though the internet was global from its inception, "national governments never really left the stage", and thus it is only a matter of resources and political will for national actors to significantly shape and manage global media. As he puts it "media can ultimately be as global as those who consume its content wish it to be". This, Flew explains, leads to the continuing coexistence of national identities and more deterritorialised, cosmopolitan versions, which all should be taken into consideration when studying the phenomenon of global media.

All in all, given the extensiveness and the complexity of the book, detailed with illustrative case studies and examples to bring the theories closer to the reader, Understanding Global Media could prove equally essential to seasoned experts seeking to deepen their knowledge of global media even further, and to newcomers from different backgrounds seeking a good entry point into the field.

Orsolya Szabó Palócz UNIVERSITY OF SZEGED, HUNGARY 